\title{
BMJ Open Analysis of caesarean section and neonatal outcome using the Robson classification in a rural district hospital in Tanzania: an observational retrospective study
}

\author{
Francesca Tognon (D) , ${ }^{1,2}$ Angela Borghero, ${ }^{3}$ Giovanni Putoto, ${ }^{2}$ Donald Maziku, ${ }^{4}$ \\ Giovanni Fernando Torelli, ${ }^{3}$ Gaetano Azzimonti, ${ }^{3}$ Ana Pilar Betran ${ }^{5}$
}

To cite: Tognon F, Borghero A, Putoto G, et al. Analysis of caesarean section and neonatal outcome using the Robson classification in a rural district hospital in Tanzania: an observational retrospective study. BMJ Open 2019;9:e033348. doi:10.1136/ bmjopen-2019-033348

- Prepublication history and additional material for this paper are available online. To view these files, please visit the journal online (http://dx.doi. org/10.1136/bmjopen-2019033348).

Received 31 July 2019 Revised 02 October 2019 Accepted 31 October 2019

D) Check for updates

(C) Author(s) (or their employer(s)) 2019. Re-use permitted under CC BY-NC. No commercial re-use. See rights and permissions. Published by BMJ.

For numbered affiliations see end of article.

Correspondence to Dr Francesca Tognon; francesca.tognon.1@phd. unipd.it

\section{ABSTRACT}

Objective Caesarean section (CS) rates have increased worldwide in recent decades. In 2015, the WHO proposed the use of the 10-group Robson classification as a global standard for assessing, monitoring and comparing CS rates both within healthcare facilities over time and between them. The aim of this study was to assess the pattern of CS rates according to the Robson classification and describe maternal and perinatal outcomes by group at the Tosamaganga Hospital in rural Tanzania.

Design Observational retrospective study.

Setting St. John of the Cross Tosamaganga Hospital, a referral centre in rural Tanzania.

Participants 3012 women who gave birth in Tosamaganga Hospital from 1 January to 30 June 2014 and from 1 March to 30 November 2015.

Results The overall CS rate was $35.2 \%$, and about $90 \%$ of women admitted for labour were in Robson groups 1 through 5 . More than $40 \%$ of the CS carried out in the hospital were performed on nulliparous women at term with a single fetus in cephalic presentation (groups 1 and 3 ), and the most frequent indication for the procedure was previous uterine scar (39.2\%). The majority of severe neonatal outcomes were observed in groups 1 (27.7\%), 10 (24.5\%) and 3 (19.1\%).

Conclusion We recorded a high CS rate in Tosamaganga Hospital, particularly in low-risk patients groups (Robson groups 1 and 3). Our analysis of Robson classification and neonatal outcomes suggests the need to improve labour management at the hospital and to provide timely referrals in order to prevent women from arriving there in critical conditions.

\section{INTRODUCTION}

Caesarean section (CS) is a lifesaving procedure performed when an urgent obstetric condition precludes vaginal delivery. ${ }^{1}$ The CS rate is widely considered an important global indicator for measuring access to obstetric services $^{2}$ and safe and timely care for mothers and newborns. Ensuring access to CS is an essential strategy to reduce maternal

\section{Strengths and limitations of this study}

- Our study used data from a rural setting, that can be compared with analogous data obtained in other settings in the country.

- The availability of outcome data, indication and data on who performed the caesarean section (CS) made possible a more contextualised interpretation of CS rates in each group.

- The combination of two different periods of 2014 and 2015 enlarged the sample size and allowed us to avoid seasonal bias.

- The data was collected from handwritten records, thus some of the information may not be accurate.

- Due to missing data, it was not possible to analyse the details of the CS decision-making process.

mortality ${ }^{3}$ in order to achieve the target of Sustainable Development Goal number, that is reducing the number of maternal deaths to less than 70 per 100000 live births by $2030 .{ }^{4}$

As surgical procedure, CS is associated with increased risk of maternal morbidity, including postpartum haemorrhage, blood transfusion, hysterectomy and even death, while a uterine scar can increase the risk of uterine rupture, placenta previa or placenta accreta in subsequent pregnancies. ${ }^{5-7}$ These risks are higher in settings that lack access to safe surgery and/or the capacity to treat complications safely. Compared with vaginal delivery, CS also necessitates more health personnel and entails higher costs both for hospitals and for society. ${ }^{8}$ Nevertheless, over the past three decades CS rates have increased steadily in many countries, especially in middle-income and high-income ones, a phenomenon that has become a major public health concern. ${ }^{910}$ In 1985 , the WHO stated that 'There is no justification for 
any region to have a caesarean section rate higher than $10 \%-15 \%$ '. This statement was justified based on review of data mainly from northern European countries which had achieved good maternal and perinatal outcomes with that CS rate. ${ }^{11}$ Numerous studies have analysed the relationship between the CS rate and maternal and neonatal mortality, attempting to define the optimal limit/range associated with minimum maternal and perinatal risks, ${ }^{12-15}$ but the multiple limitations in each of these approaches have limited the interpretation of results. ${ }^{16}$ In 2015, a new WHO policy statement superseding the earlier one did not recommend any specific rate as 'optimal', instead recommending that 'Every effort should be made to provide caesarean sections to women in need, rather than striving to achieve a specific rate'. ${ }^{1}$

Nevertheless, the above-mentioned health and socioeconomic impact as well as the unknown ecological and intergenerational consequences of the worldwide trend of increasing CS rate mean that it continues to be a widespread concern. The increase in CS deliveries is being seen not only in high-income and middle-income countries, but also in low-income ones. Moreover, the increase has not been equally distributed across income or residency strata; in low-income countries, inequalities are exacerbated by the unnecessary overuse of CS in or among some facilities, settings or patients groups alongside others where the lack of access to the procedure leads to high levels of maternal and perinatal mortality. ${ }^{17}$

Efforts have been made to devise effective strategies to reduce unnecessary CS. In order to better face this challenge, it is essential to study the population of women who undergo CS, to identify high-risk groups for poor outcomes and to investigate the reasons for these trends in different groups and settings. ${ }^{18}$ For many decades, the lack of a standard and internationally accepted CS classification system made it difficult to fully understand the growing trend and act on it. The 10-group Robson classification system now recommended by WHO and the International Federation of Gynecology and Obstetrics for assessing, monitoring and comparing CS rates within healthcare facilities over time as well as between them ${ }^{19}$ is simple, clinically relevant, accountable, replicable and verifiable, ${ }^{20}$ all critical characteristics for such a system.

The aim of our work was to assess the pattern of CS rates according to the Robson classification and to describe maternal and perinatal outcomes by group in a rural district hospital in Tanzania. Based on these data, we propose potential strategies to address the overuse of CS procedures.

\section{METHODS}

\section{Design and participants}

This was an observational retrospective study conducted in a rural district hospital in Tanzania. We included the women who gave birth in Tosamaganga Hospital from 1 January to 30 June 2014 and from 1 March to 30 November 2015. During these two periods, two Italian obstetrics and gynaecology resident doctors were available to support the hospital's maternity staff and ensure the completeness of patient charts (one during the first and one during the second period). Since a resident doctor was absent in the labour ward from July 2014 to February 2015, the information routinely collected in that period was considered inadequate for analysis and thus could not be included. Fetal position and information on previous deliveries are two important variables for the Robson classification, which were not collected and recorded systematically and routinely.

In addition, combining the two periods made it possible to increase our study population and avoid seasonal bias due to the dry and rainy season. We used the Robson classification to categorise each of the women into 1 of 10 groups. A full description of this classification system has been provided in online supplementary file 1.

\section{Setting}

St. John of the Cross Tosamaganga Hospital belongs to the Roman Catholic Church, Diocese of Iringa, and is supported in terms of governance and human resources by Doctors with Africa Collegio Universitario Aspiranti Medici Missionari, an Italian non-governmental organisation. Although the hospital is a private facility, it has been officially integrated into the Tanzanian public health system since 2007 in the context of the Private Public Partnership framework and is recognised as a Council Designated Hospital for Iringa District Council. Tosamaganga Hospital is the only Comprehensive Emergency Obstetric and Newborn Care Center in Iringa Rural District, serving an estimated population of 265000 inhabitants.

Tosamaganga Hospital handles approximately 2300 deliveries per year. The hospital had a total of 165 beds, 48 of which were in the maternity department, including 12 obstetrics, 18 in vaginal postpartum and 18 in CS postpartum. There was also a labour room and a small neonatal resuscitation room. There was no anaesthesiologist in the hospital. Paediatric ward (32 beds) was served by only one paediatrician present during the day in and on call at night.

The maternity department had two functioning operating theatres, one for major and one for minor surgical procedures (eg, dilation and curettage, dressing). Midwives monitored labour progression with the use of a partograph, and the fetal heart rate was checked through intermittent auscultation done with a pinard. An ultrasound machine was available, but was not routinely used for labour assistance. The human resources allowed to perform CS during the study included a gynaecologist, a medical doctor (MD) and five assistant medical doctors (AMD). The maternity staff included 10 midwives divided over 3 shifts ( 3 in the morning, 2 in the afternoon and 2 at night) as well as a clinical officer. In addition to Tosamaganga Hospital, there were 10 health centres (HCs) and 62 dispensaries in the district. None of them were allowed to perform CS. 
Table 1 Characteristics of women delivered during the period from January to June 2014 and March to November 2015 in Tosamaganga Hospital, Tanzania $(n=3012)$

\begin{tabular}{lc}
\hline Maternal age & 25.6 \\
Mean & $14-45$ \\
\hline Range & \\
\hline Parity & $1321(43.9 \%)$ \\
\hline Nulliparous (\%) & $1691(56.1 \%)$ \\
\hline Multiparous (\%) & \\
\hline Previous CS & $2493(82.8 \%)$ \\
\hline No previous CS (\%) & $111(3.7 \%)$ \\
\hline One previous CS (\%) & $38(1.3 \%)$ \\
\hline Two previous CS (\%) & \\
\hline Three or more previous CS (\%) & $2844(94.4 \%)$ \\
\hline Referral status & $168(5.6 \%)$ \\
\hline Self-admitted (\%) & \\
\hline Referred from other facilities (\%) & \\
\hline
\end{tabular}

CS, caesarean section.

\section{Variables and data collection}

The data were collected retrospectively from hospital registers (labour room, maternity ward and operating theatre) and patients charts in a Microsoft Excel dataextraction form specifically designed for this study (see online supplementary file 2). All data sources were compared to verify the quality of the information. For each woman who gave birth in the hospital, we collected data on maternal age, obstetric history (parity, previous CS), fetal presentation, gestational age (using the date of the last menstrual period (LMP)) and onset of labour (spontaneous, induced, pre-labour CS). Final mode of delivery was classified into two categories: vaginal delivery and CS. Vaginal delivery could have been either (1) simple vaginal delivery that included all vaginal deliveries not requiring forceps or vacuum though they may have had episiotomy and (2) operative vaginal delivery that included all vaginal deliveries that required forceps or vacuum.

For each woman who underwent a CS, a single indication was assigned as the indication for use the procedure. When more than one indication was recorded in the woman's records and hospital charts, the authors selected only one for the analysis. This was done according to a predefined hierarchy devised for this study based on earlier proposals in the literature ${ }^{182122}:$ (1) urgent or emergency CS (considering eclamptic, abrupio placentae, uterine rupture), mechanical or dynamic dystocia; (2) previous scar(s); (3) malpresentation; (4) cephalopelvic disproportion; (5) fetal distress; (6) breech; (7) twins and (8) others. We collected maternal outcomes (death before discharge), neonatal outcomes (birth weight, Apgar score at 1 and $5 \mathrm{~min}$, death before discharge) and referral status (formally referred from village-level dispensaries, rural HCs or self-referred).

Since the date of LMP was missing from most of the records ( $\mathrm{n}=2444 ; 81.1 \%$ ), we used birth weight $\geq 2500 \mathrm{~g}$ as a proxy for gestational age $\geq 37$ weeks. ${ }^{23}$ This adaptation has been suggested and previously used for the Robson classification in settings where it is challenging to assign gestational age accurately. ${ }^{24-26}$

Exclusion criteria were birth weight $<500 \mathrm{~g}$ (proxy for gestational aged $<22$ weeks). No data were collected on congenital malformations and all cases were included. For twin deliveries, only the first twin's outcome was taken into account.

The caesarean delivery rate was defined as the number of caesarean deliveries over the total number of live births. ${ }^{915}$ The maternal mortality rate was defined as the number of maternal deaths over the total number of women who gave birth regardless of birth outcome. We defined a neonatal composite outcome: severe neonatal outcome as the total number of stillbirths, early neonatal deaths (death of a live born neonate, by discharge or day 7 of life whichever occurred first) and birth discharged alive with an Apgar score of $<7$ at 5 min. The data available did not allow us to differentiate between fresh and macerated stillbirths. Deaths occurring after discharge were not captured. During the 2015 study period (1 March to 30 November), information was also collected on who performed the CS (gynaecologist, MD, AMD).

Each woman was categorised into 1 of 10 groups using the Robson classification. ${ }^{27}$ We used the recommended subdivision for groups 2 and 4 into induced labour (2a or $4 \mathrm{a}$ ) and pre-labour CS (2b or $4 \mathrm{~b}$ ). Group 5 was also divided into 5.1 (women with only one previous CS) and 5.2 (women with two or more previous CS) ${ }^{27}$ We analysed intrapartum and postpartum perinatal mortality by type of delivery and using the Robson classification.

\section{Patient and public involvement}

No patients/members of the public were involved in the definition of the research question or outcome measures, nor in the design and implementation of the study. We have no plans to involve patients/members of the public in the dissemination of the study's results.

\section{RESULTS}

From 1 January to 30 June 2014 and from 1 March to 30 November 2015, 3052 women gave birth in the Tosamaganga Hospital. Complete information was available for $3012(98.7 \%)$ of these deliveries, all of which were included in the Robson classification. The CS rate in the population included in our analysis was $35.2 \%$ of all births.

Table 1 summarises the characteristics of the study population. The mean age of the women was 25.6 years (range 14-45 years). Among all deliveries, 1691 women were multiparous $(56.1 \%), 370(12.3 \%)$ had undergone 


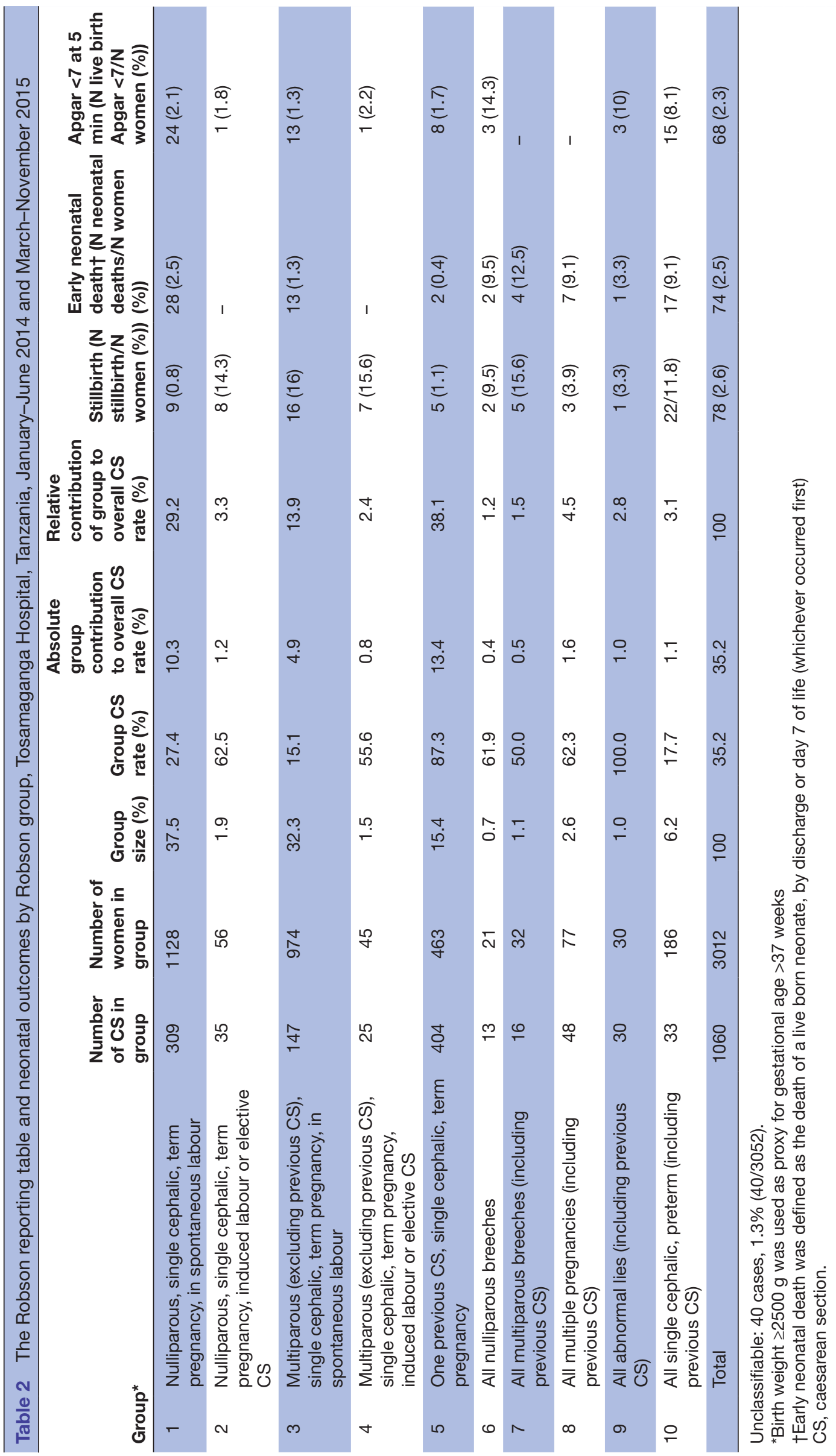


1 previous CS, 111 (3.7\%) had undergone 2 previous CS and $38(1.3 \%)$ had undergone 3 or more CS (table 1 ).

Table 2 shows the Robson classification. Almost $90 \%$ of the women admitted for delivery in this hospital were classified into groups 1 through 5 and about two-thirds into groups 1 through 4.

Of the nulliparous women with a term singleton fetus in cephalic presentation $(\mathrm{n}=1184), 1128(95.3 \%)$ went into labour spontaneously, $32(2.7 \%)$ were induced and $24(2 \%)$ had a pre-labour CS (tables 2 and 3). Similarly, of the multiparous women with a term singleton fetus in cephalic presentation $(\mathrm{n}=1019), 974(95.6 \%)$ went into labour spontaneously, 21 (2\%) were induced and 24 (2.4\%) had a pre-labour CS.

Women admitted in the hospital for delivery with a term singleton fetus in cephalic presentation who entered labour spontaneously accounted for $70 \%$ of the obstetric population. They had CS rates of $27.4 \%$ and $15.1 \%$ in nulliparous and multiparous, respectively.

We analysed and interpreted the Robson table and the data according to the Robson classification interpretation guidelines published by $\mathrm{WHO}^{2728}$ which is shown in table 4.

Women in group 5 (previous CS) constituted about $15 \%$ of the obstetric population of the hospital, with a CS rate of $87 \%$. Two-third of these women had undergone just one previous CS while one-third had undergone two or more CS (tables 2 and 3).

Overall, the most frequent indication for performing a CS was one or more previous CS $(39.2 \%)$, followed by dystocia $(22.3 \%)$ and then fetal distress $(12.8 \%)$ (table 5$)$.

The management of the women with previous CS is shown in figure 1 . During the study, there were 519 $(17.2 \%)$ women with one or more previous CS. One hundred and fifty three of them $(29.5 \%)$ had an elective pre-labour CS, while the rest $(70.5 \%)$ went into labour spontaneously. None of these women were induced. Among those who entered labour spontaneously 71 (19.4\%) had a spontaneous vaginal delivery, while 295 $(80.6 \%)$ had a CS. The indication recorded for the CS was 'previous CS' in $97.4 \%$ of the women who had a prelabour CS and $90.5 \%$ of the women who went into labour spontaneously (figure 1).

More than $40 \%$ of all CS in the hospital occurred in groups 1 and 3 . Since the CS rate was particularly high for group $1(27.7 \%)$ and group $3(15.2 \%)$, we carried out an in-depth analysis regarding the indication for the $\mathrm{CS}$ in these two groups (figure 2). The majority of them were performed for dystocia $(44.3 \%$ in group $1 ; 55.1 \%$ in group 3). Among the 168 women referred from other facilities, 107 (63.7\%) delivered by CS.

We recorded two maternal deaths (one in group 1 and one in group 5) and 152 perinatal deaths (5\%) of which $78(2.6 \%)$ were stillbirths and $74(2.5 \%)$ were neonatal deaths. About $70 \%$ of all perinatal deaths occurred in groups 1 (37 deaths), 3 (29 deaths) and 10 (39 deaths). We analysed 220 cases of severe neonatal outcome (stillbirths, neonatal deaths and live births with Apgar score 
Table 4 Interpretation of the Robson classification in Tosamaganga Hospital, Tanzania, January- June 2014 and MarchNovember 2015 following the WHO Robson Classification Interpretation Manual

Quality of data The CS rate of the group is $100 \%$ indicating a good quality of data.

Type of population The size of groups 1 and $2(39.5 \%)$ is within the expected range. However, the ratio of the size of group 1 vs that of group 2 is very high (20.1). In the WHO Multicountry Study reference population (population in the WHO study with relatively low CS rates as well as good labour and childbirth outcomes), this ratio was found to be $6.3 .{ }^{27} 43$ Similarly, the ratio of the size of group 3 vs that of group 4 is 21.6 -very high compared with 6.3 in the WHO study. ${ }^{27} 43$ Both high rates probably indicate the need to increase inductions in these groups of women (term with singleton fetus in cephalic presentation) or even to avoid performing pre-labour CS. This is consistent with the high CS rates found in groups 1 and 3 and our data on stillbirth and neonatal deaths. Despite their being lower-risk groups, $37(24 \%)$ and $29(19 \%)$ of the total 152 perinatal deaths that occurred during the study period were in groups 1 and 3 , respectively. Only group 10 had a larger number of perinatal deaths with $39(25.7 \%)$ but this is a high-risk group where the women had singleton pregnancies in cephalic presentation preterm.

- The size of groups 3 and 4 is 33.9\%. Since Tanzania has a high fertility rate, we expected a higher number of multiparous women. This can be explained by the very high size of group $5(15.4 \%)$ with a CS rate of $87 \%$, which contributes to about $38 \%$ of all the CS performed in the hospital.

- The size groups 6 and 7 is $1.6 \%$, which is below the expected range for breeches. Moreover, the ratio of group 6/group $7(0.5)$ is unusual since breeches are more frequent in nulliparas than multiparas. This could indicate errors in data collection potentially due to misclassification of nulliparous women with breech presentation into group 1.

- The size of group 10 is $6.2 \%$ that is slightly higher than that proposed by Robson (5\%) and that found in the WHO Study (4.2\%). Even if Tosamaganga Hospital is a referral hospital, only 168 women (5.6\%) were referred, $107(63.7 \%)$ of whom delivered by CS. For this reason, we consider that the larger sizes of groups 8 and 10 cannot be justified by a particularly high-risk population.

- Malnutrition and other concurrent diseases may have caused growth retardation and errors in pregnancy dating based on neonatal weight.

Caesarean section rate

- In all groups, the CS rates are higher than the expected range. ${ }^{2743}$

- It has been proposed that CS rates in group 1 of about $10 \%$ are achievable. However, the above-mentioned high ratio of group 1 vs group 2 may be responsible for the high CS rate (27.4\%) in this group. If insufficient numbers of women are induced or have necessary pre-labour CS, it is more likely that these women will need a CS at a later stage of labour. In addition, the high CS rate in group 2 is not caused by the size of group $2 \mathrm{~b}$ (pre-labour CS, only $0.8 \%$ of the population), but mainly by a very low size of group $2 \mathrm{a}(1.1 \%$ of the population) and by the poor success for induction with a consequent high C/S rate (34.4\%) in this group as well. Similar arguments apply to groups 3 and 4 . The high CS rate in group $4(55.5 \%)$ is not justified by the high size of group $4 \mathrm{~b}$ (which accounted for only $0.8 \%$ of the population), but by the small size of group 4 a (just $0.7 \%$ of the population). Particularly in groups 1 and 3 , a large number of CS were performed with the diagnosis of dystocia. This might indicate a poor quality of diagnosis of dystocia and suboptimal management of the active phase of labour.

- The very high CS rate in group $5(87.2 \%)$ is not justified by the proportion of women with two or more CS (group 5.2) who make up one-third of this group. CS rates in women with one CS (group 5.1) and two or more CS (group 5.2) are both high (83.2\% and $97 \%$, respectively), indicating the common practice of performing CS in women with previous scar. These rates contrast markedly with the $50 \%-60 \%$ rates considered appropriate by the Robson guideline and the $74.4 \%$ found in the WHO Study. ${ }^{27} 43$ Nevertheless, an assessment of the hospital's capacity to offer safe trial of labour after CS (TOLACs) is crucial prior to making recommendation that more women be offered one VBAC was minimally practiced probably due to the inadequate number of midwives available to attend women in labour. Moreover, the lack of information regarding previous caesarean deliveries (how they were performed and whether or not complications occurred) may have exacerbated doctor's fear regarding whether to offer a TOLAC.

- Looking at the higher-risk groups, the CS rate in group 8 is within the expected range, while the CS rate in group 10 is lower than expected, probably indicating a high rate of spontaneous preterm labour or a high incident of low birth weight (since newborn weight was used as a proxy for gestational age). ${ }^{2743}$

- Considering the contribution of the groups to the overall CS rate, groups 1, 2 and 5 account for $70.6 \%$ of all $\mathrm{CS}$, a higher percentage than expected, and of that figure, group 5 accounts for $38.1 \%$ indicating, as already mentioned, a very high CS rate in the previous years.

CS, caesarean section; VBAC, vaginal birth after caesarean.

$<7$ after $5 \mathrm{~min}$ ) by mode of delivery using the Robson classification as shown in table 6. A major contribution to severe neonatal outcome was made by groups $1(27.7 \%)$, $10(24.5 \%)$ and $3(19.1 \%)$. Considering the incidence in each category, the groups with the highest severe neonatal outcome rate were groups $6(33.3 \%), 7(28.1 \%)$, indicating a high risk for newborn in breech deliveries and $10(29 \%)$ for preterm babies. The incidence of severe neonatal outcome was similar when analysed by mode of delivery. The majority of adverse neonatal outcomes in these groups occurred while performing simple vaginal delivery. 
Table 5 Indication for CS in the study population,

Tosamaganga Hospital, Tanzania, January-June 2014 and March-November 2015

\begin{tabular}{lrr}
\hline Previous scar & 416 & $39.2 \%$ \\
\hline Mechanical or dynamic dystocia & 236 & $22.3 \%$ \\
\hline Fetal distress & 136 & $12.8 \%$ \\
\hline Breech & 22 & $2.1 \%$ \\
\hline Twins & 28 & $2.6 \%$ \\
\hline Malpresentation & 41 & $3.9 \%$ \\
CPD & 90 & $8.5 \%$ \\
\hline Urgent or emergency CS & 50 & $4.7 \%$ \\
\hline Others & 41 & $3.9 \%$ \\
\hline Total number of CS & 1060 & $100.0 \%$ \\
\hline
\end{tabular}

CPD, cephalopelvic disproportion; CS, caesarean section.

We conducted a descriptive analysis on a subset of women who underwent CS during the 2015 study period. Information on the individual who performed the CS and the indication for the CS was available for 574 of the 616 CS conducted $(93.1 \%)$. Most of the CS were performed by a MD $(66.6 \%$; 382$)$, while $25.8 \%$ (148) were conducted by an AMD and $7.7 \%$ (44) by a gynaecologist. This distribution remains when stratifying by Robson groups and by CS indication (see online supplementary file 3 ).

\section{DISCUSSION}

Our analysis of 3012 deliveries in a rural district hospital in Tanzania using the Robson classification showed a 35\% overall CS rate in an obstetric population of about $90 \%$ in Robson groups 1 through 5 . These groups were arguably

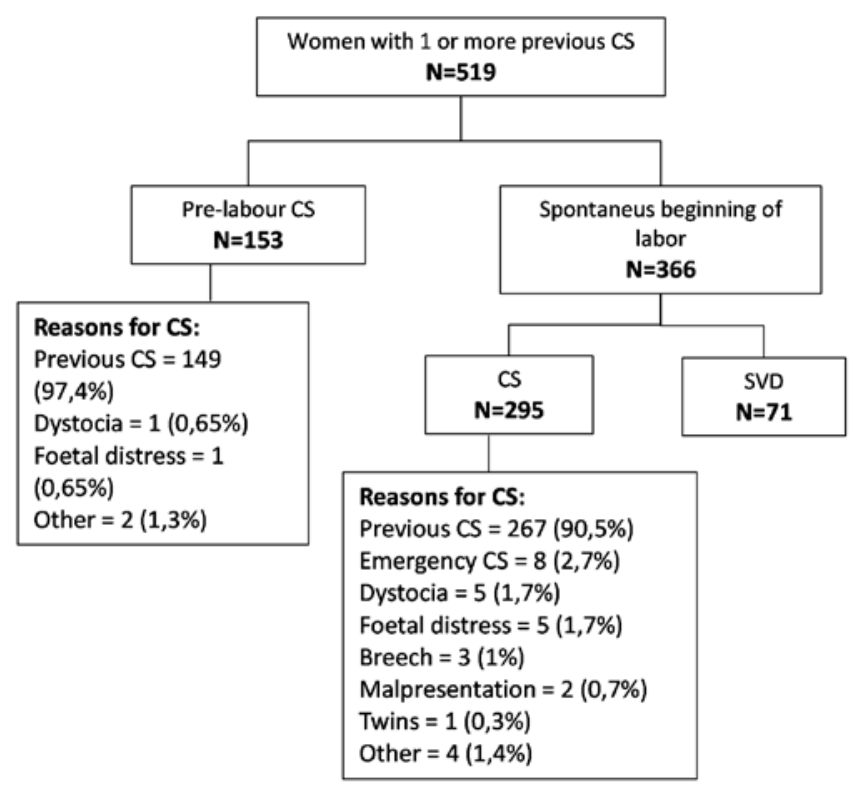

Figure 1 Management of women with one or more previous caesarean sections during the study period.

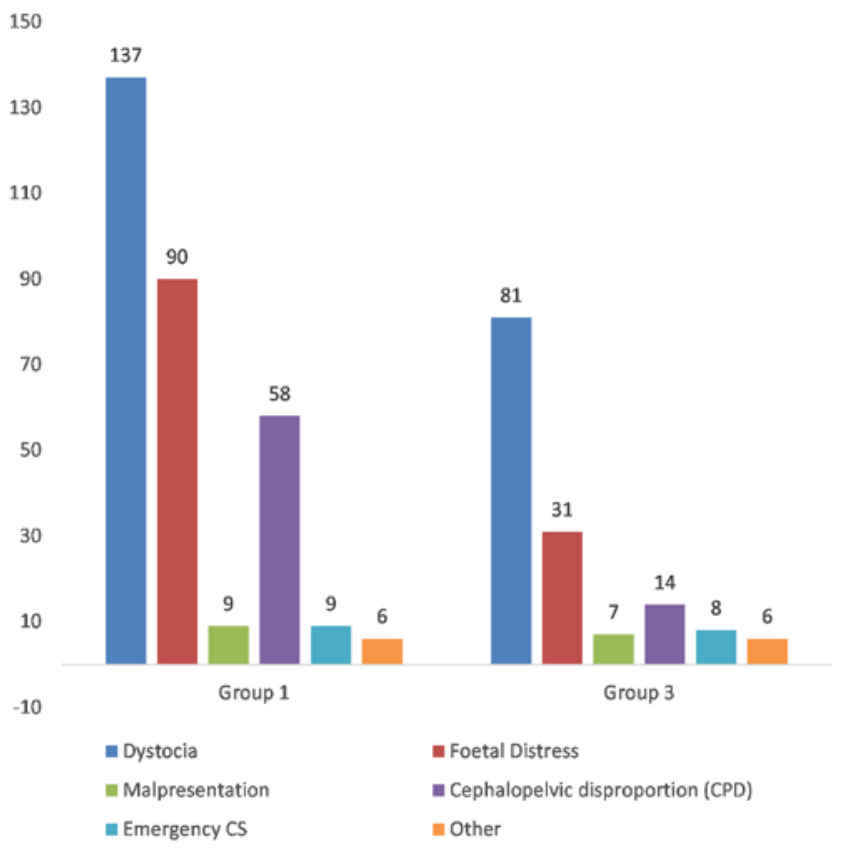

Figure 2 Indication for caesarean section in groups 1 and 3.

composed of low-risk women, but they presented high CS rates, for example, $27.4 \%$ and $15.1 \%$ in groups 1 and 3 , respectively, who were women at term with a single fetus in cephalic presentation without previous CS who entered labour spontaneously.

High CS rates have been reported in other studies conducted in Tanzania ${ }^{25}{ }^{29}$ (eg, 31\% at the Muhimbli Hospital and $35 \%$ in Kilimanjaro Christian Medical Center (KCMC)) probably because of the role played by a referral hospital in targeting high-risk pregnancies. This hypothesis could be confirmed by the higher CS rate in women referred from other facilities $63.7 \%$ in our study). Sørbye et al described the situation at the $\mathrm{KCMC}^{30}$ comparing patients who were referred and self-referred, with CS rates of $55 \%$ and $26.9 \%$, respectively. However, the referral system seems to have played a minimal role in the setting of our study since only $5.6 \%$ of the women were referred (vs $20 \%$ in the Sørbye study).

Nilsen $e t a t^{29}$ hypothesises that poor quality of care at the dispensary and $\mathrm{HC}$ level contributes to increasing the number of preventable CS in women who are referred late and in critical condition, meaning that by the time they get to the medical facility an emergency CS is the only possible action. ${ }^{31}$ In addition, several studies have highlighted the inadequacy of obstetric and neonatal care services at the primary level in Tanzania. ${ }^{32-34}$ In a 2009 study conducted in the Kusulu district, ${ }^{35}$ Kruk et al showed that $42.2 \%$ of women who gave birth in peripheral units bypassed the nearest services (dispensaries) in favour of higher-level facilities (HCs), governmental or private facilities. $61.4 \%$ of women who gave birth at home had a government dispensary in the village, but chose not to go there for their deliveries. 
Table 6 Distribution of severe neonatal* outcomes by Robson group classification

\begin{tabular}{|c|c|c|c|c|c|c|c|c|c|}
\hline \multirow{2}{*}{$\frac{\text { Group }}{1}$} & \multirow{2}{*}{$\begin{array}{l}\text { Number of severe } \\
\text { neonatal outcomes/ } \\
\text { number of women in } \\
\text { group } \\
61 / 1128\end{array}$} & \multirow{2}{*}{$\begin{array}{l}\begin{array}{l}\text { Proportion } \\
\text { of severe } \\
\text { neonatal } \\
\text { outcomes }\end{array} \\
5.4 \%\end{array}$} & \multirow[t]{2}{*}{$\begin{array}{l}\text { Relative } \\
\text { contribution } \\
\text { of group to } \\
\text { the overall } \\
\text { severe } \\
\text { neonatal } \\
\text { outcomes } \\
27.7 \%\end{array}$} & \multicolumn{2}{|c|}{$\begin{array}{l}\text { Proportion of severe } \\
\text { neonatal outcome } \\
\text { in simple vaginal } \\
\text { deliveries } / \text { total } \\
\text { simple vaginal } \\
\text { deliveries }\end{array}$} & \multicolumn{2}{|c|}{$\begin{array}{l}\text { Proportion of } \\
\text { severe neonatal } \\
\text { outcome in } \\
\text { operative } \\
\text { vaginal } \\
\text { deliveries } ¥ \text { / } \\
\text { total operative } \\
\text { vaginal } \\
\text { deliveries }\end{array}$} & \multicolumn{2}{|c|}{$\begin{array}{l}\text { Proportion of } \\
\text { severe neonatal } \\
\text { outcome in CS / } \\
\text { total CS }\end{array}$} \\
\hline & & & & 43/799 & $5.4 \%$ & $1 / 20$ & $5.0 \%$ & $17 / 309$ & $5.5 \%$ \\
\hline 2 & $9 / 56$ & $16.1 \%$ & $4.1 \%$ & $7 / 19$ & $36.8 \%$ & $0 / 2$ & $0.0 \%$ & $2 / 35$ & $5.7 \%$ \\
\hline 3 & $42 / 974$ & $4.3 \%$ & $19.1 \%$ & 27/818 & $3.3 \%$ & $1 / 9$ & $11.1 \%$ & $14 / 147$ & $9.5 \%$ \\
\hline 4 & $8 / 45$ & $17.8 \%$ & $3.6 \%$ & $7 / 20$ & $35.0 \%$ & - & - & $1 / 25$ & $4.0 \%$ \\
\hline 5 & $15 / 463$ & $3.2 \%$ & $6.8 \%$ & $1 / 58$ & $1.7 \%$ & $0 / 1$ & $0.0 \%$ & $14 / 404$ & $3.5 \%$ \\
\hline 9 & $5 / 30$ & $16.7 \%$ & $2.3 \%$ & - & & - & - & $5 / 30$ & $16.7 \%$ \\
\hline 10 & $54 / 186$ & $29.0 \%$ & $24.5 \%$ & $47 / 153$ & $30.7 \%$ & - & - & $7 / 33$ & $21.2 \%$ \\
\hline Total & $220 / 3012$ & $7.3 \%$ & $100.0 \%$ & $149 / 1920$ & $7.8 \%$ & $2 / 32$ & $6.3 \%$ & $69 / 1060$ & $6.5 \%$ \\
\hline
\end{tabular}

*Severe neonatal outcome includes stillbirths, neonatal deaths and live births with Apgar score $<7$ after 5 min.

†Simple vaginal delivery: vaginal deliveries not requiring forceps or vacuum, though episiotomy may have been done. $\ddagger$ Operative vaginal delivery: vaginal deliveries that required forceps or vacuum.

CS, caesarean section.

Studies conducted by Straneo et al in the Tosamaganga catchment area showed high rates of institutional birth coverage, probably facilitated by the high health facility density. ${ }^{36}$ However, coverage and quality do not always go together and the poorest women were reported accessing lower-level health services for birth where quality of care is suboptimal due to limited caseloads and poor staffing. ${ }^{37}$

Comparing our study population according to the Robson classification with those in similar settings, Tosamaganga Hospital shows a bigger size of group 5 (15.4\% compared with $8.8 \%$ in Muhimbli Hospital ${ }^{25}$ ) and a smaller size of preterm births ( $6.2 \%$ vs $14.6 \%)$, while the size of groups 2 and 4 was similar, a probable confirmation of the low induction rate in both settings.

Severe neonatal outcomes were recorded for 220 newborns, almost half of them in groups 1 and 3, which may indicate that a high CS rate in these groups did not guarantee better quality of care and was not accompanied by better neonatal outcomes. This is consistent with the phenomenon of 'Perinatal Paradox' which has been described in the literature ${ }^{3839}$ as the inconsistency between 'our superb ability to care for the individual patient and our dismal failure to address the problems of the larger society'. ${ }^{39}$ The overuse of unnecessary technology in low-risk women translates in that the growing number of surgical procedures being performed are not associated with significant improvements in terms of maternal and neonatal outcomes.
Among 152 perinatal deaths, 78 were stillbirths. The highest incidence of severe neonatal outcome was recorded in groups 6, 7 and 10; therefore, in our hospital breech deliveries and preterm deliveries were the most at risk. As has been shown by other studies in similar setting, ${ }^{40}$ a higher risk for adverse neonatal outcome in breech vaginal deliveries compared with breech CS was recorded in Tosamaganga Hospital, suggesting suboptimal management of breech presentation and the need for training to improve the skills of the providers. In addition, it underlines the need for appropriate, highquality antenatal healthcare programmes to encourage women to come to the facility earlier in order to identify, monitor and better manage risk factors for preterm birth, pregnancies with fetuses in breech presentation and also decrease the number of intrapartum deaths and macerated fetuses.

In Tosamaganga Hospital most of the CS were performed by the personnel incharge of the delivery room, namely the MD and the AMD, who handled all duty calls. The gynaecologist was involved in case of emergency and complicated elective or intrapartum CS. In all Robson categories, the highest CS rate was performed by the MD. Again, this suggests the need for obstetric and gynaecological training for the staff and a closer supervision by the gynaecologist. Nyamtema et al analysed the work of the MD, AMD and midwives in 10 rural HCs in Tanzania. ${ }^{41}$ Based on Tanzanian national guidelines 
and WHO recommendations, ${ }^{42} 37 \%$ of CS were considered unnecessary and preventable. After a staff training programme was carried out and closer supervision provided, the proportion of unnecessary CS fell from $30 \%$ to $17 \%$ in HCs and from $37 \%$ to $20 \%$ in hospitals. ${ }^{41}$

\section{Strengths and limitations}

This study used data from a rural setting that can be compared with analogous population type described in other settings in the country. The availability of outcome data and the indication for CS made possible a more contextualised interpretation of CS rates in each group. Moreover, the availability of data on who performed the CS made it possible to specifically intervene in this aspect where appropriate. There were a number of limitations to this study. The data was collected retrospectively from handwritten records and some of the information may not have been recorded accurately. Due to deficient routine data collection, we included two different time periods (January-June 2014 and March-November 2015) in the study, meaning that there was discontinuity in data collection. Combining the two periods enlarged our sample size and allowed us to avoid bias due to seasonal differences. Some variables were not available in patient charts and registers (eg, length of labour, who made the decision to perform the CS or whether the stillbirth was macerated or fresh). Perinatal mortality may have been under-reported since early neonatal deaths occurring after discharge were not recorded. Data on congenital malformations were not available, making the interpretation of neonatal outcomes more difficult. Lastly, in the absence of reliable data on gestational age, we used birth weight as a proxy, a technique found in the literature on earlier studies conducted in low-resource settings.

\section{CONCLUSION}

We found a high CS rate at Tosamaganga Hospital even though the obstetric population served was not considered particularly high risk for a referral hospital. Our analysis of the data using the Robson classification showed that groups 1 and 3 (women at term with a single fetus in cephalic presentation who entered labour spontaneously) were larger than anticipated and presented very high CS rates. The large size of these groups and high CS rates combined with the stillbirth and neonatal mortality rates seen in the hospital may indicate insufficient induction rates and the need to provide more timely referrals so that women will get to the hospital before their conditions have become too critical.

Efforts to improve care and outcomes should include greater investment in the training of medical and nursing staff to improve the management of labour, with a correct use of the partograph and in particular for the judicious use of oxytocin augmentation in the management of prolonged labour. Training on the management of breeches and TOLAC should also be a priority in order to improve the quality of intrapartum care in the hospital.

\section{Author affiliations}

${ }^{1}$ Dipartimento di Salute della Donna e del Bambino, Universita degli Studi di Padova Dipartimento di Medicina, Padova, Italy

${ }^{2}$ Research Unit, Cuamm Medici con I'Africa, Padova, Veneto, Italy

${ }^{3}$ Tosamaganga Council Designated Hospital, Cuamm Medici con I'Africa, Iringa, United Republic of Tanzania

${ }^{4}$ Maternity Department, Tosamaganga Council Designated Hospital, Iringa, United Republic of Tanzania

${ }^{5}$ UNDP/UNFPA/UNICEF/WHO/World Bank Special Programme of Research, Development and Research Training in Human Reproduction (HRP), Reproductive Health and Research, World Health Organization, Geneva, Switzerland

Acknowledgements We would like to thank the hospital management and Maternity Unit staff for their support in the implementation of this study.

Contributors FT, AB and GP contributed to the concept and design of the study. BA collected data. FT analysed the data. FT and BA drafted the manuscript. DM, GP, GFT and GA supervised and provided mentorship. APB assisted with the literature research and revision of the manuscript. All authors read and approved the final version of the manuscript.

Funding The authors have not declared a specific grant for this research from any funding agency in the public, commercial or not-for-profit sectors.

Competing interests None declared.

Patient consent for publication Not required.

Ethics approval This study was approved by the Tosamaganga Hospital Review Board, who, in accordance with the 'Declaration of Helsinki', waived the need for the written consent of the patients, given the study's retrospective nature and the collection of anonymised data. The approval was signed on 22 January 2019, Ref $n$. DOIRA/TCDH/NOL/28/201.

Provenance and peer review Not commissioned; externally peer reviewed.

Data availability statement Data are available upon reasonable request.

Open access This is an open access article distributed in accordance with the Creative Commons Attribution Non Commercial (CC BY-NC 4.0) license, which permits others to distribute, remix, adapt, build upon this work non-commercially, and license their derivative works on different terms, provided the original work is properly cited, appropriate credit is given, any changes made indicated, and the use is non-commercial. See: http://creativecommons.org/licenses/by-nc/4.0/.

ORCID iD

Francesca Tognon http://orcid.org/0000-0001-6649-1525

\section{REFERENCES}

1 Betran AP, Torloni MR, Zhang JJ, et al. WHO statement on caesarean section rates. BJOG 2016;123:667-70.

2 Bailey PE, Paxton A. Program note. Using UN process indicators to assess needs in emergency obstetric services. Int J Gynaecol Obstet 2002;76:299-305.

3 Thomas S, Meadows J, McQueen KAK. Access to cesarean section will reduce maternal mortality in low-income countries: a mathematical model. World J Surg 2016;40:1537-41.

4 United Nations General Assembly. Transforming our world: the 2030 agenda for sustainable development, 2015. Available: https:// www.un.org/ga/search/view_doc.asp?symbol=A/RES/70/1\&Lang=E [Accessed Jan 2019].

5 Villar J, Carroli G, Zavaleta N, et al. Maternal and neonatal individual risks and benefits associated with caesarean delivery: multicentre prospective study. BMJ 2007;335.

6 Kennare R, Tucker G, Heard A, et al. Risks of adverse outcomes in the next birth after a first cesarean delivery. Obstet Gynecol 2007;109:270-6.

7 Daltveit AK, Tollånes MC, Pihlstrøm H, et al. Cesarean delivery and subsequent pregnancies. Obstet Gynecol 2008;111:1327-34.

8 Allen VM, O'Connell CM, Farrell SA, et al. Economic implications of method of delivery. Am J Obstet Gynecol 2005;193:192-7.

9 Betrán AP, Ye J, Moller A-B, et al. The increasing trend in caesarean section rates: global, regional and national estimates: 1990-2014. PLoS One 2016;11:e0148343.

10 Vogel JP, Betrán AP, Vindevoghel N, et al. Use of the Robson classification to assess caesarean section trends in 21 countries: a 
secondary analysis of two WHO multicountry surveys. Lancet Glob Health 2015;3:e260-70.

11 WHO. Appropriate technology for birth. Lancet 1985;2:436-7.

12 Ghahiri A, Khosravi M. Maternal and neonatal morbidity and mortality rate in caesarean section and vaginal delivery. Adv Biomed Res 2015;4:193.

13 Ye J, Zhang J, Mikolajczyk R, et al. Association between rates of caesarean section and maternal and neonatal mortality in the 21st century: a worldwide population-based ecological study with longitudinal data. BJOG 2016;123:745-53.

14 Vogel JP, Souza JP, Mori R, et al. Maternal complications and perinatal mortality: findings of the world Health organization multicountry survey on maternal and newborn health. BJOG 2014;121(Suppl 1):76-88.

15 Ye J, Betrán AP, Guerrero Vela M, et al. Searching for the optimal rate of medically necessary cesarean delivery. Birth 2014;41:237-44.

16 Betran AP, Torloni MR, Zhang J, et al. What is the optimal rate of caesarean section at population level? A systematic review of ecologic studies. Reprod Health 2015;12:57.

17 Ogundele OJ, Pavlova M, Groot W. Examining trends in inequality in the use of reproductive health care services in Ghana and Nigeria. BMC Pregnancy Childbirth 2018;18:492.

18 Torloni MR, Betran AP, Souza JP, et al. Classifications for cesarean section: a systematic review. PLoS One 2011;6:e14566.

19 FIGO Working Group On Challenges In Care Of Mothers And Infants During Labour And Delivery. Best practice advice on the 10-group classification system for cesarean deliveries. Int J Gynaecol Obstet 2016;135:232-3.

20 Robson MS. Classification of caesarean sections. Fetal Matern Med Rev 2001;12:23-39.

21 Anderson GM, Lomas J. Determinants of the increasing cesarean birth rate. Ontario data 1979 to 1982. N Engl J Med 1984;311:887-92.

22 Althabe F, Belizán JM, Villar J, et al. Mandatory second opinion to reduce rates of unnecessary caesarean sections in Latin America: a cluster randomised controlled trial. Lancet 2004;363:1934-40.

23 WHO. Physical status: the use and interpretation of anthropometry. Technical report series No. 854. Available: https://apps.who.int/iris/ bitstream/handle/10665/37003/WHO_TRS_854.pdf?sequence=1 [Accessed Mar 2019].

24 Tura AK, Pijpers O, de Man M, et al. Analysis of caesarean sections using Robson 10-group classification system in a university hospital in eastern Ethiopia: a cross-sectional study. BMJ Open 2018;8:e020520.

25 Litorp H, Kidanto HL, Nystrom L, et al. Increasing caesarean section rates among low-risk groups: a panel study classifying deliveries according to Robson at a university hospital in Tanzania. BMC Pregnancy Childbirth 2013;13:107.

26 Hanson C, Betrán AP, Opondo C, et al. Trends in caesarean section rates between 2007 and 2013 in obstetric risk groups inspired by the Robson classification: results from population-based surveys in a low-resource setting. BJOG 2019;126:690-700.

27 WHO. Robson classification: implementation manual. Geneva: World Health Organization, 2017. https://apps.who.int/iris/bitstream/handle/ 10665/259512/9789241513197-eng.pdf?sequence $=1$
28 WHO. Robson classification: example of Robson report table with interpretation. Geneva: World Health Organization, 2017. https:// apps.who.int/iris/bitstream/handle/10665/259513/WHO-RHR-17.22eng.pdf?sequence $=1$

29 Nilsen C, Østbye T, Daltveit AK, et al. Trends in and sociodemographic factors associated with caesarean section at a Tanzanian referral Hospital, 2000 to 2013. Int J Equity Health 2014;13:87.

30 Sørbye IK, Vangen S, Oneko O, et al. Caesarean section among referred and self-referred birthing women: a cohort study from a tertiary Hospital, northeastern Tanzania. BMC Pregnancy Childbirth 2011;11:55

31 Betrán AP, Temmerman M, Kingdon C, et al. Interventions to reduce unnecessary caesarean sections in healthy women and babies. Lancet 2018;392:1358-68.

32 National Bureau of Statistics (NBS) [Tanzania] and Macro International Inc. Tanzania service provision assessment survey 2006 Dar es Salaam, Tanzania: National Bureau of Statistics and Macro International Inc, 2007. https://dhsprogram.com/pubs/pdf/SPA12/ SPA12.pdf

33 Leonard KL, Masatu MC. Variations in the quality of care accessible to rural communities in Tanzania. Health Aff (Millwood) 2007;26:w380-92

34 Gilson L, Alilio M, Heggenhougen K. Community satisfaction with primary health care services: an evaluation undertaken in the Morogoro region of Tanzania. Soc Sci Med 1994;39:767-80

35 Kruk ME, Mbaruku G, McCord CW, et al. Bypassing primary care facilities for childbirth: a population-based study in rural Tanzania. Health Policy Plan 2009;24:279-88.

36 Straneo M, Fogliati P, Pellis I, et al. On the way to universal coverage of maternal services in Iringa rural district in Tanzania. Who is yet to be reached? Afr Health Sci 2016;16:420-8.

37 Straneo M, Fogliati P, Azzimonti G, et al. Where do the rural poor deliver when high coverage of health facility delivery is achieved? Findings from a community and hospital survey in Tanzania. PLoS One 2014;9:e113995.

38 Rosenblatt RA. The perinatal paradox: doing more and accomplishing less. Health Aff 1989;8:158-68.

39 Kliegman RM. Neonatal technology, perinatal survival, social consequences, and the perinatal paradox. Am J Public Health 1995;85:909-13.

40 Högberg U, Claeson C, Krebs L, et al. Breech delivery at a university hospital in Tanzania. BMC Pregnancy Childbirth 2016;16:342.

41 Nyamtema A, Mwakatundu N, Dominico S, et al. Increasing the availability and quality of caesarean section in Tanzania. BJOG 2016;123:1676-82.

42 WHO. Managing complications in pregnancy and childbirth: a guide for midwives and doctors. 2nd edn. Geneva: World Health Organization, 2017. https://apps.who.int/iris/bitstream/handle/10665/ 255760/9789241565493-eng.pdf?sequence=1

43 Souza JP, Betran AP, Dumont A, et al. A global reference for caesarean section rates (C-Model): a multicountry cross-sectional study. BJOG 2016;123:427-36 